\title{
Emerging Scholar Best Article Award, 2015
}

\author{
Roger J. R. Levesque ${ }^{1}$
}

Received: 15 October 2015 / Accepted: 15 October 2015/Published online: 19 October 2015

(C) Springer Science+Business Media New York 2015

The editors of the Journal of Youth and Adolescence are delighted to announce the 2015 recipient of its Emerging Scholar Best Article Award. The Journal presents the award to the article's lead author, who must be an "emerging scholar" (i.e., an untenured researcher, such as a graduate student, post-doctoral scholar, research scientist, or assistant professor). The recipient of the award is selected by a random group of editorial board members who evaluate manuscripts' innovative and substantive contributions to the empirical understanding of adolescence. In addition to receiving the recognition from colleagues, the winner receives a financial award generously provided by Springer, the journal's publisher.

The 2015 winner is Paul A. Chase, for his article entitled "Academic achievement in the high school years: The changing role of school engagement", which was co-authored with Lacey J. Hilliard, G. John Geldhof, Daniel J. A. Warren, and Richard M. Lerner (Chase et al. 2014). His study developed a tripartite-behavioral, emotional, and cognitive-model of school engagement to assess the relationship between school engagement and academic success among high school students. His analyses used data from the 4-H study of positive youth development, which in this instance followed 710 youth (69\% female) from Grades 10 to 12 . The results revealed that the components of school engagement and academic achievement were mutually predictive and that these predictions varied from grade to grade. Overall, behavioral engagement emerged as the strongest predictor of achievement, leading the authors to conclude that "the best approach for capitalizing on the

\footnotetext{
Roger J. R. Levesque

rlevesqu@indiana.edu

1 Indiana University, Bloomington, IN, USA
}

reciprocal relations between school engagement and academic achievement" may be "initiatives that promote intrinsic motives for behavioral engagement, coupled perhaps, at least initially, with extrinsic incentives for such engagement" (Chase et al. 2014, p. 894).

Given that the journal publishes 12 issues per year, each typically containing up to 15 manuscripts, the editors view the award as a considerably distinctive accomplishment. Each of the issues has multiple articles authored by emerging scholars. The selection of articles for the award involves a two-step process, with the first round involving the selection of the strongest articles from each issue and the second round involving another group of editors who rank the selected articles. As in prior years (see Levesque 2011, 2012, 2013, 2014), the process resulted in a pool of very impressive articles. Unlike prior years, the initial round resulted in having one of the journal issues creating a tie between two authors, Madan et al. (2014) and Young (2014). A look at their work reveals why the selection committee was impressed.

The articles selected as potential winners addressed a variety of important topics that reflect the journal's commitment to better understanding adolescent development from contextual perspectives. Some of the articles focused on a variety of influences on developmental outcomes, such as ethnicity/race (Killoren and Deutsch 2014; Williams et al. 2014; Moilanen et al. 2014), genetics (Newsome and Sullivan 2014), media (Scull et al. 2014; Madan et al. 2014) and social networks, particularly peers (Sentse et al. 2014; Caravita et al. 2014; Garnett et al. 2014). In doing so, the studies focused on a variety of outcomes, including academic success (Godfrey and Grayman 2014; Chase et al. 2014) and a variety of risk behavior, including selfharm (Hamza and Willoughby 2014) as well as violence, delinquency and substance use (Sentse et al. 2014; Garnett 
et al. 2014; Madan et al. 2014; Young 2014; Scull et al. 2014; Moilanen et al. 2014; Newsome and Sullivan 2014). As in the past, most finalists adopted longitudinal approaches, complex research designs, and innovative statistical analyses to understand developmental issues. Some, which reveals an emerging trend in the journal, adopted explicitly experimental designs.

On behalf of the editorial board, I again would like to congratulate Paul Chase and his colleagues for their success that comes at a remarkable time in the growth of our journal and field.

Conflict of interest The author reports no conflict of interest.

\section{References}

Caravita, S. C., Sijtsema, J. J., Rambaran, J. A., \& Gini, G. (2014). Peer influences on moral disengagement in late childhood and early adolescence. Journal of Youth and Adolescence, 43(2), 193-207.

Chase, P. A., Hilliard, L. J., Geldhof, G. J., Warren, D. J., \& Lerner, R. M. (2014). Academic achievement in the high school years: The changing role of school engagement. Journal of Youth and Adolescence, 43(6), 884-896.

Garnett, B. R., Masyn, K. E., Austin, S. B., Miller, M., Williams, D. R., \& Viswanath, K. (2014). The intersectionality of discrimination attributes and bullying among youth: an applied latent class analysis. Journal of Youth and Adolescence, 43(8), $1225-1239$.

Godfrey, E. B., \& Grayman, J. K. (2014). Teaching citizens: The role of open classroom climate in fostering critical consciousness among youth. Journal of Youth and Adolescence, 43(11), 1801-1817.

Hamza, C. A., \& Willoughby, T. (2014). A longitudinal personcentered examination of nonsuicidal self-injury among university students. Journal of Youth and Adolescence, 43(4), 671-685.

Killoren, S. E., \& Deutsch, A. R. (2014). A longitudinal examination of parenting processes and Latino youth's risky sexual behaviors. Journal of Youth and Adolescence, 43(12), 1982-1993.
Levesque, R. J. R. (2011). Emerging scholar best article award, 2011. Journal of Youth and Adolescence, 40, 565-1567.

Levesque, R. J. R. (2012). Emerging scholar best article award, 2012. Journal of Youth and Adolescence, 41, 1557-1559.

Levesque, R. J. R. (2013). Emerging scholar best article award, 2013. Journal of Youth and Adolescence, 42, 1910-1912.

Levesque, R. J. R. (2014). Emerging scholar best article award, 2014. Journal of Youth and Adolescence, 43, 2091-2092.

Madan, A., Mrug, S., \& Wright, R. A. (2014). The effects of media violence on anxiety in late adolescence. Journal of Youth and Adolescence, 43(1), 116-126.

Moilanen, K. L., Markstrom, C. A., \& Jones, E. (2014). Extracurricular activity availability and participation and substance use among American Indian adolescents. Journal of Youth and Adolescence, 43(3), 454-469.

Newsome, J., \& Sullivan, C. J. (2014). Resilience and vulnerability in adolescents: Genetic influences on differential response to risk for delinquency. Journal of Youth and Adolescence, 43(7), 1080-1095.

Scull, T. M., Kupersmidt, J. B., \& Erausquin, J. T. (2014). The impact of media-related cognitions on children's substance use outcomes in the context of parental and peer substance use. Journal of Youth and Adolescence, 43(5), 717-728.

Sentse, M., Kiuru, N., Veenstra, R., \& Salmivalli, C. (2014). A social network approach to the interplay between adolescents' bullying and likeability over time. Journal of Youth and Adolescence, 43(9), 1409-1420.

Williams, J. L., Aiyer, S. M., Durkee, M. I., \& Tolan, P. H. (2014). The protective role of ethnic identity for urban adolescent males facing multiple stressors. Journal of Youth and Adolescence, 43(10), 1728-1741.

Young, J. T. N. (2014). "Role magnets"? An empirical investigation of popularity trajectories for life-course persistent individuals during adolescence. Journal of Youth and Adolescence, 43(1), 104-115.

Roger J. R. Levesque Professor of Criminal Justice and (Affiliate) Law at Indiana University, serves as Editor of the Journal of Youth and Adolescence and Adolescent Research Review. 